\title{
Comparative Effectiveness of Contextual and Structural Method of Teaching Vocabulary
}

\author{
Malik Behlol (Corresponding author) \\ Visiting Faculty Member, International Islamic, University Islamabd \\ Mohammad Munir Kaini \\ International Islamic, University Islamabd
}

\begin{abstract}
The study was conducted to find out effectiveness of contextual an, structural method of teaching vocabulary in English at secondary level. It was an experimental study in which the pretest posttest design was used. The population of the study was the students of secondary classes studying in Government secondary schools of Rawalpindi District. Purposive and random sampling was applied to select the school and subjects. The significance of difference between the scores of groups at 0.05 level was tested applying $t$ test. The study revealed that the contextual method is more useful for high achievers (HA) whereas structural method is more useful for average and low achievers. The HA performed better with the contextual method due to study of words in different contexts and taking help from contextual clues that has prompted spoken and written fluency. Better performance of the average and low achievers with the structural method was due to the morphological analyses of a word, role of the students as the partner in the learning process, generation and active processing of vocabulary, provision of multiple exposure of different intensity for practice and personalization of word learning.
\end{abstract}

Keywords: Vocabulary, Effectiveness, Contextual method, Structural method

\section{Introduction}

Knowledge and skill of using words in different contexts play an important role in the comprehension of new concepts, ideas and principles. Students are greatly benefited in their studies that have got expertise in the use of words in different context. Laufer (1997) states that vocabulary is one of the most important aspects of language learning and language use. In fact, it is what makes the essence of a language. It is generally divided into active and passive vocabulary. Passive vocabulary consists of those words that the students may recognize and understand when they occur in the context, but which he/she cannot produce or use correctly in different contexts. The active vocabulary consists of those words which the students understand, recall at will, write with correct spellings, can pronounce correctly, and use constructively in speaking and writing. Different studies revealed that lack of command on vocabulary become the cause of communication breakdown (Balochowicz \& Fisher 2000; Naghy \& Scott 2000). Therefore, the linguists are showing greater interest for vocabulary learning as a component of every language. It is a significant component of standardized language tests; methodologists and program planners are working to find out the most effective ways to promote understanding of vocabulary. The teachers teaching second language follow varieties of techniques and methods for teaching vocabulary. They include rote rehearsal, the use of visual aids, role-playing, vocabulary learning in a specific cultural context etc. Different techniques and methods are effective in different contexts and situations. For this purpose, the researcher decided to conduct a study to find out the comparative effectiveness of contextual and structural methods of teaching vocabulary.

\section{Objectives of the study}

The objectives of the study were to find out the:

1) comparative effectiveness of contextual and structural methods of teaching vocabulary at secondary level

2) effectiveness of contextual and structural methods of teaching vocabulary on the performance of high, average and low achievers

3) the retention rate of high, average and low achievers taught with the contextual and structural methods of teaching vocabulary

\subsection{Hypotheses of the study}

To achieve the objectives of the study, following null hypotheses were tested:

1) There is no significant difference between the mean scores of the students taught with the contextual and structural methods of teaching vocabulary 
2) There is no significant difference between the mean scores of the high achievers taught with the contextual and structural methods of teaching vocabulary

3) There is no significant difference between the mean scores of the low achievers taught with the contextual and structural methods of teaching vocabulary

4) There is no significant difference between the mean scores of the average achievers taught with the contextual and structural methods of teaching vocabulary

\section{Review of Literature}

According to Weatherford (1990), context based approach of vocabulary learning saves a lot of time of the learner which is wasted in going to dictionary again and again. Contextual evidence helps the learner to guess the meanings of the new words. It is based on teaching the meanings of new words by having them used in different contexts surrounding the words. There are two types of context: Pedagogical context/ Instructional context and natural context. The instructional context refers to sentences specifically written to introduce the meanings of the new words. The natural context refers to text sentences written to communicate ideas of the text. To understand the meanings of the new words, the students need to know the information related to the topic in which the words are embedded. The contextual framework helps to explain the meanings of difficult words by giving explanation in the preceding or very next sentence in simple language. For example, she speaks without break and do not give chance to anybody else to speak in the meeting. She is really a loquacious lady. In this respect, referent words, synonyms, antonyms, hyponyms, definitions, alternative and restatement help to reach at the meanings of the words. Context based approach not only helps the reader to know the meaning of the words but also help and facilitate in the use of them. It develops independent learning habits, inculcate problem solving approach and promote active learning process. The words that have got different meanings with the same spellings and pronunciation are very difficult to be learnt without context based approach. For example, the word pen is also used as a noun and verb, and at the same time it has also got the meanings of $a$ shed. In the same way, the sentence such as his fur coat was coated with ice. He left her alone on the left bank of the river. There is no point in drying your clothes if they are already dry. She pointed at me and made a very pointed remark. She drew the curtains to make the room lighter, and then lighted her cigarette with a lighter. After he had drunk the whisky, the drunk was very drunk indeed. The referee who refereed the match matched the toughness of the player. It is very difficult to memorize the meanings of the words without any context. In the sentences above, the contextual information helps the learner to understand the meanings of the words that have got different meanings.

According to Filmore and Snow (2000), structural approach of teaching vocabulary is based on the morphological analyses of the word. It is a process of breaking the words into prefixes, root and suffixes to illustrate the meanings. It is considered easy and practical approach of vocabulary building. The morphological features of the language such as prefixes, suffixes, and roots help the learner to identify the meanings. The students do not analyze the sentences to find out the meanings of the word but analyze the word to follow its meanings. Knowledge about the root form of the word helps them to build up their vocabulary in logical and in sequenced way. After getting command over the root form of the word, there is no more difficulty to modify it as different parts of speech and build up the vocabulary. The words that are generated by the learner can be recalled easily as compared to the words that are merely listened or read. It is, therefore, necessary that the students must be provided opportunities to generate new words from the given exercises. For example, the students might be asked to form adjectives and adverbs from nouns or verbs. These exercises will greatly improve the vocabulary of the students. In the same way punctuation marks also help the reader to understand the meanings of difficult words such as Full stop indicates the completion of the thought, comma indicates continuation of the thought and semi colon, colon indicate the reversal of the thought.

The author (2010) has identified four principles of vocabulary instruction for personalizing word learning. These principles are related to active development of vocabulary that demands actual use of new words in different contexts to conduct personal matters. The students themselves decide what word to learn and how to learn. The second principle demands immersing of the students in the vocabulary learning. It means ongoing commitment for the vocabulary learning throughout the working day in different forms. It is done when language is not only exposed but explained to students. The third principle is based on the view that word building needs multiple exposure of different intensity. A single exposure is not enough to develop rich understanding of vocabulary. It takes place in many steps over a period of time. Each exposure adds information, how the word is used in different contexts. There is need of 12 exposures for getting mastery and proper utilization of new lexical items. The students must be provided opportunities to reflect on the learnt lexical item and to relate them with the previous knowledge. There is also need to limit the presentation of vocabulary in a lesson or the whole academic year. The massive exposure of 
vocabulary may confuse the students in the use of words in spoken and written form. The last principle emphasizes that the students may be involved and participates in the process of learning vocabulary. They should be active participant and co-learner in learning the new vocabulary. They should be encouraged to make connection between their learnt and previous knowledge. It allows students to experiment with words in different ways.

According to Scott and Nagy (1997), conceptual approach focuses on the learning of concepts instead of literal definitions of the words. The proponents of this approach believe that mere learning meanings of a word without conceptual clarity are not enough to integrate the new knowledge with the existing one. It does not make the learner able to fully comprehend the meanings of word and get sufficient skill to use it. Conceptual approach explains the meanings of the word after passing through three stages. It starts with the information what students already know about the new word. The second step is connecting information with the previous information or schemata that already exist in the brain for identifying a concept. The conclusion is drawn by comparing and contrasting information to find out similarities and differences at third stage. It makes the learner able to add in the existing body of concepts or to revise it in the light of drawn conclusions.

According to Nagy \& Scot (1997), traditional practices of vocabulary leaning are based on the definitional approach. The focus of this approach is to learn the meanings of the words either looking up in dictionary or glossary or by drill. It is considered the easiest and less time consuming approach of vocabulary learning. It saves time of teacher as well as of the students and makes them able to study maximum words in minimum time. However, it is not a guarantee that this approach improves comprehension of the students and increases the active vocabulary of the learner. Sometimes, learning definition is not necessarily helpful in the integration of the knowledge. There is a need of background information for the integration of the knowledge. According to Herman \& Dole (1988), dictionaries are poor tool of learning the meanings of the new words. It does not develop the skill to personalize the word and its use in different contexts. It only enables the learner to know its meanings without knowing its use. According to Watt (1995), definitional instructions of teaching vocabulary are based on description or statement of word-meaning not of its usage. The teacher provides a list of words and the students consult dictionary to know their meanings. They are not taught to use the word in different contexts.

According to Chun (1996) and Wallace (1988), the learnt words must fulfill the following requirements. It can be recognized by the learner in spoken form, recalled at will, used in different contexts with correct grammatical form, spelled correctly, pronounced in recognizable form and know its connotation and association. Grains \& Redman (1993) identified certain groupings criteria which will be helpful for the teacher and the students in learning the vocabulary in the process of second language learning. They say that words can be grouped in different ways: relating to the topic, grouped as an activity or process, similar in meaning, items which form pairs, items on scale or cline which illustrate difference in degree, items with in word families, grouping on notational similarity, items which connect discourse, items forming set of idioms or multi-word verbs, grouping by spelling difficulty, grouping on the basis of phonological patterns, grouping on the basis of stylistics, etc. Mezyenski (1983) has identified some factors relating to the success of vocabulary instruction in improving reading comprehension. They were (a) the amount of practice given in the learning of words (b) the breadth of training in the use of words and (c) the degree to which active processing is encouraged.

According to Rosenfield (1988), emotions play an important role in recalling the new lexical items. The new learnt vocabulary can be easily recalled when they are linked to positive and negative emotions. These emotions are considered as happy and sad events in life. However, it does not mean any threatening, frightening or intimidating environment in which the brain starts "down shifting" and the brain cells cannot obtain sufficient blood. This condition does not help to recall the new vocabulary items. Semantics is the study about the meanings of the words. The common notion about the meanings, according to the linguists that words refer to things such as ball, earth, apple, room, boy etc. There are some words that do not fall into this category. They are such as abstract nouns i-e for example, honesty, beautiful, fantastic, difficult, easy etc. The second view about the explanation of the meanings that some words are not directly linked to things rather they are connected to ideas and then things. In this process, the relationship is only made through mind. They believe for every word there is some concept.

\section{Design of the study}

Pretest Posttest Control Group Design was used for this study. Methods of teaching vocabulary and the academic achievement were two variables of this study. Methods of teaching were independent variable and academic achievement was dependent variable of the study. The students taught with contextual method were named as a group A and the students taught with the structural method were named as group B. The researcher developed 40 lesson plans for contextual and structural methods of vocabulary teaching (20 for each). The lesson plans were 
validated getting the opinions of the experts. They are the experts of English language teaching working in the universities of Islamabd (Dr, Ali Hassan, Dr. Samina Qadir, Dr. Arshad, Mr. Nazik Hussain). Posttest scores were compared to determine the effectiveness of the contextual and structural methods of vocabulary teaching. Random assignment and the presence of pretest and control group serve to control for all sources of internal and external invalidity such as history, maturation, testing, differential regression, mortality, statistical regression, testing AND Instrumentation.

\subsection{Population and Sampling}

The poulation of this study comprised the students studying in Urdu medium public Secondary schools of district Rawalpindi. The population was entirely homogenous because curriculum, assessment system and facilities available for the students were also the same. Two sections A and B with 56 students of the $10^{\text {th }}$ class from Government High School Tench Bhatta, Rawalpindi were taken as a sample of the study. Purposive sampling technique was applied to select the school because of following reasons: the principal of the school allowed to conduct the experiment, he also allowed to change the sections of the students to adjust them in the groups, availability of more than 54 students studying English at $10^{\text {th }}$ grade, availability of conducive environment for experiments of study and six English teachers were also available and willing to participate in the study. The students were equated on pretest scores applying matching technique.

\subsection{Formulation of groups}

Two groups were formulated to conduct this study. They were equated on the basis of pretest scores. Matching technique was used to equalize the groups. To find out the effectiveness of the methods of teaching on different ability groups: the students of the two groups were further split into high, low and average categories. The students who obtained 60 or above marks were put in the category of high achievers, 45 to 59 were put in the category average and less than 45 were considered low achievers.

\subsection{Research Instrument}

A test was constructed by the researcher and it was used as a pretest, posttest and retention test at different times according to the objectives of the study. The test was pilot tested in three schools on 103 students of the $10^{\text {th }}$ class. As a result of pilot testing, a few of the items were modified and deleted. The opinions of the 05 experts were also obtained to validate the test. The test was used as a pretest to equalize the groups and it was also used as a posttest to find out the effectiveness of the teaching methods. The test carried completion items, multiple choice items, true false items, short questions, matching items. To cover the interaction of time of measurement and treatment effects, the delayed/retention test was used to control this external threat to validity of the study. The purpose of this test was to know whether the result remained significant in comparison of posttest at a later date.

\subsection{Selection and Training of Teachers}

The factors taken into considerations for the selection of two English teachers were educational qualifications, teaching experience at secondary level, results at the SSC level examination conducted by the Board of Intermediate and Secondary Education Rawalpindi (result of the sessions 2006 to 2009), teaching in classroom, interaction patterns in the classroom with the students, communication skills, rapport with the students. The teachers were voluntarily assigned to teach the two groups after conducting training sessions with them. The teachers were briefed about the basic principles of the two methods. They were trained how to break the words into prefixes, root and suffixes to illustrate the meanings. It is a process of analyzing word not the sentence to find out its meanings. The components of contextual method and training sessions are also conducted with the teacher who was assigned to teach the group A.

\subsection{Collection and Analysis Data}

The raw scores obtained from pretest, posttest and retention test were the data of this study. Time allotted for the test was one hour and 20 minutes, and total score of the test was 100 . Scoring key was developed to mark the test. The raw scores obtained from the pretest, posttest and retention test were analyzed through SPSS. The means, standard deviations and differences of means were computed for each group. Significance of difference between the mean scores of both the experimental and control groups were tested at 0.05 level by applying in dependent sample $t$ test.

\section{Analyses and Interpretation of Data}

The data of the study is analyzed under the following tables:

Table 1: Significance of difference between the mean scores of all the categories of experimental and control groups on pretest 
The table reveals the means, standard deviations and standard error of the means and difference of the means of two groups on pretest. The mean of the group A was found 47.1 and that of group B was 47.92, the mean of the high achievers (HA) of the group A and group B were 63.5 and 63.66, the average achievers (AA) were 50.33 and 51.66, and the low achievers (LA) were 33.44 and 34.0 respectively. The standard deviations of the group A and group B were 12.12 and 12.09, HA of the group A and B were 3.56 and 4.67, AA of the group A and group B were 3.2 and 3.42 and LA were 4.47 and 3.59. The standard errors of the means of the group A and group B were 2.29 and 2.28, HA of the group A and group B were 1.45 and 1.9, AA of the group A and group B were .932 and .987 , and of the LA of the group A and group B were 1.41 and 1.13 respectively. It revealed that as far as the mean, SD and SEM of both the groups were concerned, they were very close to each other. The difference between the mean scores of the two groups on pretest was insignificant. The degree of freedom of the two groups as a whole was 54, HA of the groups was 10, AA of the groups was 22 and the LA of the groups was 18. The p values were found .801, .946, .335 and .745 on 0.05 level which was insignificant. Hence, it was discovered that there was no significant difference between the mean scores of the two groups, high achievers, average achievers and the low achievers of the groups. It was established that the significant difference was not found between the performance of the group A and group B on pretest.

Table 2: Significance of difference between the mean scores of all the categories of experimental and control groups on posttest

The table reveals the means, standard deviations, standard error of the means and difference of the means of two groups on posttest. The mean of the group A was found 55.75 and that of group B was 66.82, the mean of the high achievers of the group A and group B were 79.5 and 69.5, the average achievers were 57.16 and 73.16 , and the low achievers were 39.8 and 57.6 respectively. The standard deviations of the group A and group B were 8.67 and 15.47, HA of the group A and group B were 2.42 and 4.76, AA of the group A and group B were 5.11 and 5.79 and LA were 4.68 and 4.37. The standard errors of the means of the group A and group B were 1.63 and 2.92, HA of the group A and group B were .991 and 1.94, AA of the group A and group B were 1.47 and 1.67, and of the LA of the group A and group B were 1.48 and 1.38 respectively. It was revealed that as far as the mean, SD and SEM of both the groups were concerned, they were different. The degree of freedom of the group A and group B was 54, HA of the groups was 10, AA of the groups was 22 and the LA of the groups was 18 . The $p$ values were found $.002, .001, .000$ and .000 on 0.05 level which was significant. Hence, it was discovered that there was significant difference between the mean scores of group A and group B, high achievers, average achievers and the low achievers of the experimental and control groups. The null hypothesis on the posttest "there is no significant difference between the performance of the students taught with the contextual method of vocabulary teaching and structural method of vocabulary teaching was" rejected. These results also supported by the study conducted by Weatherford (1990) that the contextual method of teaching vocabulary promoted interest in learning because it explains the meanings of the difficult words with the help of contextual clues. The results of the study were also verified by the studies conducted by Ali (2005). He has concluded that the high achievers learn more through the contextual method of teaching vocabulary because they themselves actively participate in the learning process and build up their vocabulary. He found that the high ability students were highly motivated and performed better by studying through the contextual method of teaching vocabulary.

However, the structural method was found more effective for average and low achievers who performed better on posttest. The results also supported the studies conducted by Fillmor \& Snow (2000). They discovered that the structural method of teaching vocabulary promoted interest in learning because it focuses on the root form of the word and breaks it into prefixes and suffixes which are helpful for average and low achievers. It also helps the student to build up their vocabulary not through rote learning method but real understanding of the base form of the word.

Table 3: Significance of difference between the mean scores of all the categories of experimental and control groups on retention test

The table reveals the means, standard deviations, standard error of the means and difference of the means of two groups on retention test. The mean of the group A was found 51.78 and that of group B was 61.85 , the mean of the high achievers of the group A and group B were 76.5 and 66.33, the average achievers were 52.33 and 67.08 , and the low achievers (LA) were 36.3 and 52.9 respectively. The standard deviations of the group A and group B were 15.64 and 8.52, HA of the group A and group B were 3.98 and 4.71, AA of the group A and group B were 5.1 and 6.52 and LA were 4.44 and 3.81. The standard errors of the means of the group A and group B were 2.95 and 1.61, HA of the group A and group B were 1.62 and 1.92, AA of the group A and group B were 1.47 and 1.88, and of the LA of the group A and group B were 1.4 and 1.2 respectively. It revealed that as far as the mean, SD and SEM of both the groups were concerned, they were different. The degree of freedom of the group A and group B was 54, 
HA of the groups was 10 , AA of the groups was 22 and the LA of the groups was 18 . The p values were found $.004, .002, .000$ and .000 on 0.05 level which was significant. Hence, it was discovered that there was significant difference between the mean scores of group A 1 and group B, High achievers, average achievers and the low achievers of the group A and group B. The null hypothesis on the retention test "there is no significant difference between the performance of the students taught with the contextual method of vocabulary teaching and structural method of vocabulary teaching was" rejected.

\section{Conclusions}

Following were the conclusions of the study:

1) The study reveals significant difference between the performances of the students taught with the contextual and structural method of teaching. The high achievers who were taught with the contextual method performed better as compared to the performance of the high achievers who were taught with the structural method of teaching vocabulary. The better performance of the high achievers was due to understanding of the meanings of the words with the help of contextual clues in a sentence and in the paragraph as a whole. It also saves precious time of the student that is wasted in going to the dictionary again and again which is a barrier in the development of conceptual schemata.

2) The average and low achievers who were taught with the structural method performed better on posttest as compared to the low achievers who were taught with the contextual method. The better performance of the low achievers may be attributed to the breaking of the word into root, prefixes and suffixes. The average and low achievers were more confident to obtain conceptual clarity of the root form of the word and add into the vocabulary bank by the use of prefixes and suffixes. They were not competent enough to take help from the contextual clues to understand the meanings of the words.

3) Better performance of the high achievers in the EG is also due to the role of the students and teacher as a partner and co-learner in the learning process. They were themselves the manager of their own learning. The teacher plays the role of a facilitator in the learning activity. They not only learn the passive knowledge of the words but also the different usage of the word also It is based on teaching the meanings of new words by having them used in different contexts surrounding the words. It has promoted and encouraged the students to experiment with the words for its comprehension and understanding. They are found confident in tackling the linguistic problems presented to them in the learning activities and performed significantly better on posttest.

4) The retention rate of the high achievers taught with the contextual method of teaching vocabulary was better as compared to the performance of the students who were taught with structural method. It is reflected from the better performance of the students in the contextual method that they have greater interests and involvement in the learning process. They personalize word learning. They are engaged in active, independent process of vocabulary learning.

5) The students who were taught with the contextual method have reflected greater spoken and written fluency of the language because the difficult words are explained by giving summary of it. The learnt words were recognized by the learner in spoken and written form and also recalled by the learner at will. The learner is able to relate and use it in different contexts, use it in correct grammatical form, spell it correctly, pronounce it in recognizable form and aware of its connotation and association. It also promotes spoken and written fluency

6) There are some words which have different meanings with the same spelling and pronunciation that can only be learnt with the help of contextual method. For example, the word pen, spring, coat, left, bank, point, dry, light, drunk, referee and match etc.

\section{Recommendations}

Following are the recommendations of the study:

1) Teacher Training Institutions may conduct workshops for the training of the teachers to apply contextual and structural method of teaching vocabulary in the classroom. The focus of the training programme may be on the morphological analyses and the use of words in different contexts.

2) The English teachers may be trained to design the learning activities to provide oral practice on the basis of morphological and contextual analyses of words to their students. The learning activities may be graded in the way that fulfill the needs of high and low achievers.

3) Contextual method may be applied for high achievers and structural method may be followed for teaching average and low achievers. 
4) Libraries may be strengthened and enriched with sufficient books on the contextual and structural Method of Teaching Vocabulary. The Heads of the educational institutions may be provided special funds to perform this responsibility.

5) There is a need of further research studies in the topic controlling some other variables such as attitude, background status of the student, level of intelligence and gender variation.

\section{References}

Allen, V. (1983). Techniques in teaching vocabulary. New York: Oxford University Press.

Brett, A \& Rothlein, L. (1996). Vocabulary acquisition from listening to stories and explanations of target Words. The Elementary School Journal, (96) 4,67-85.

Balochowicz, C., \& Fisher, P. (2000). Teaching vocabulary. Manhwah, NJ: Erlbaum

Brown, T. S. \& Perry, F. L. (1991). A comparison for three language strategies for ESL vocabulary acquisition. TESOL Quarterly, (25).4, 655-670

Chun, D.M. (1996). Effects of multimedia annotations on vocabulary acquisition. The Modern Language Journal, (80)2, 65-80.

Doff, A. (1989). An Introduction to English language Teaching. Cambridge University Press. New York.

Fillmore, L. W. \& Snow, C. E. (2000). What Teacher Heed to Know about Language. Eric Special Report No: ED-99-CO-0008. Washington, D.C.

Grains, R \& Redman, S. (1993) Working with Words. : Oxford: Oxford University Press.

Herman, R.A. \& Dole, J. (1988). Theory and practice in vocabulary learning and in instruction. The University of Chicago. The Elementary School Journal, (89)1, 43-45.

Laufer, B. (1997). The Lexical Plight in Second Language Reading. Cambridge: Cambridge University Press.

Mezyenski, K. (1983). Issues Concerning the Acquisition of Knowledge: Effects of Vocabulary Training on Reading Comprehension. Champaign, University of Illonois.

Naghy, W. \& Scott, J. A. (2000). Scott, J.A., Noel, D.J. \& Asselin, M. 2003. Vocabulary Instruction throughout the day in 23 Upper Elementary classrooms. The Elementary school Journal, (VOL)103, 3. University of Chichago

Rivers, W. M. (1981). Foreign language skills. Chicago: University of Chicago Press.

Wallace, M. (1988). Teaching Vocabulary. Chicago: University of Chicago Press.

Weatherford, H.J. (1990). Techniques for learning vocabulary. New York: Oxford University Press.

Table 1. Significance of difference between the mean scores of all the categories of experimental and control groups on pretest

\begin{tabular}{|c|c|c|c|c|c|c|c|c|}
\hline \multirow{2}{*}{ Group } & \multirow{2}{*}{ Achiever's Level } & \multirow{2}{*}{$\mathbf{N}$} & \multirow{2}{*}{$\mathbf{M}$} & \multirow{2}{*}{ SD } & \multirow{2}{*}{$\mathbf{S E}_{M}$} & \multicolumn{3}{|c|}{$t$ test } \\
\hline & & & & & & $\mathbf{t}$ & df & p. value \\
\hline Experimental Group & Whole group & 28 & 47.1 & 12.12 & 2.29 & 250 & 51 & 001 \\
\hline Control Group & Whole group & 28 & 47.92 & 12.09 & 2.28 & .234 & 34 & .001 \\
\hline Experimental Group & High Achievers & 5 & 63.5 & 3.56 & 1.45 & 060 & 10 & 04 \\
\hline Control Group & High Achievers & 5 & 63.66 & 4.67 & 1.9 & .069 & 10 & .940 \\
\hline Experimental Group & Average Achievers & 12 & 50.33 & 3.2 & .932 & 086 & 27 & 225 \\
\hline Control Group & Average Achievers & 12 & 51.66 & 3.42 & .987 & 980 & 22 & כ5נ. \\
\hline Experimental Group & Low Achievers & 10 & 33.4 & 4.47 & 1.41 & & & \\
\hline Control Group & Low Achievers & 10 & 34.0 & 3.59 & 1.13 & .331 & 18 & .745 \\
\hline
\end{tabular}


Table 2. Significance of difference between the mean scores of all the categories of experimental and control groups on posttest

\begin{tabular}{|c|c|c|c|c|c|c|c|c|}
\hline \multirow[b]{2}{*}{ Group } & \multirow[b]{2}{*}{ Achiever's Level } & \multirow[b]{2}{*}{$\mathbf{N}$} & \multirow[b]{2}{*}{$\mathbf{M}$} & \multirow[b]{2}{*}{ SD } & \multirow[b]{2}{*}{$\mathbf{S E}_{\mathbf{M}}$} & \multicolumn{3}{|l|}{$t$ test } \\
\hline & & & & & & $\mathbf{t}$ & df & $\begin{array}{l}P \\
\text { Value }\end{array}$ \\
\hline Experimental Group & Whole group & 28 & 55.75 & 8.67 & 1.63 & 200 & 50 & (200? \\
\hline Control Group & Whole group & 28 & 66.82 & 15.47 & 2.92 & 5.302 & 34 & .002 \\
\hline Experimental Group & High Achievers & 6 & 79.5 & 2.42 & .991 & & & \\
\hline Control Group & High Achievers & 6 & 69.5 & 4.76 & 1.94 & 4.50 & & .001 \\
\hline Experimental Group & Average Achievers & 12 & 57.16 & 5.11 & 1.47 & 717 & 92 & 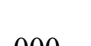 \\
\hline Control Group & Average Achievers & 12 & 73.16 & 5.79 & 1.67 & 1.17 & 22 & .000 \\
\hline Experimental Group & Low Achievers & 10 & 39.8 & 4.68 & 1.48 & 077 & 10 & 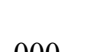 \\
\hline Control Group & Low Achievers & 10 & 57.6 & 4.37 & 1.38 & & & \\
\hline
\end{tabular}

Table 3. Significance of difference between the mean scores of all the categories of experimental and control groups on retention test

\begin{tabular}{|c|c|c|c|c|c|c|c|c|}
\hline \multirow[b]{2}{*}{ Group } & \multirow[b]{2}{*}{ Achiever's Level } & \multirow[b]{2}{*}{$\mathbf{N}$} & \multirow[b]{2}{*}{$\mathbf{M}$} & \multirow[b]{2}{*}{ SD } & \multirow[b]{2}{*}{$\mathbf{S E}_{M}$} & \multicolumn{3}{|l|}{ t test } \\
\hline & & & & & & $\mathbf{t}$ & df & $\begin{array}{l}\mathbf{p} \\
\text { value }\end{array}$ \\
\hline Experimental Group & Whole group & 28 & 51.78 & 15.64 & 2.95 & ( م) & $E$ & 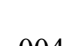 \\
\hline Control Group & Whole group & 28 & 61.85 & 8.52 & 1.61 & 2.99 & 34 & .004 \\
\hline Experimental Group & High Achievers & 6 & 76.5 & 3.98 & 1.62 & 403 & 10 & 007 \\
\hline Control Group & High Achievers & 6 & 66.33 & 4.71 & 1.92 & 4.05 & 10 & .002 \\
\hline Experimental Group & Average Achievers & 12 & 52.33 & 5.1 & 1.47 & (s) & 02 & 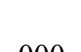 \\
\hline Control Group & Average Achievers & 12 & 67.08 & 6.52 & 1.88 & 0.10 & 22 & .000 \\
\hline Experimental Group & Low Achievers & 10 & 36.3 & 4.44 & 1.4 & 805 & 18 & 000 \\
\hline Control Group & Low Achievers & 10 & 52.9 & 3.81 & 1.2 & & & \\
\hline
\end{tabular}

